\title{
Ego, Moral, and Faith Development in Near-Death Experiencers: Three Case Studies
}

\author{
Rosalie D. Newsome, Ph.D. \\ Walden University, Minneapolis, $M N$
}

\begin{abstract}
Near-death experiencers (NDErs) commonly report shifts in basic values and attitudes, toward intensified compassion and a sense of unconditional love, spirituality, and a sense of mission, and away from materialism and competitiveness. Some researchers have suggested that these attitudinal shifts represent a new stage in human evolution, which will produce major social change. However, knowledge of these reputed NDE aftereffects has been based on NDErs' subjective reports, unverified by objective measures. This study examined relationships between three NDErs' levels of moral, ego, and faith development, as measured by standardized instruments, and extensive qualitative data describing their NDEs and personal attributes. The results suggest that currently available instruments, designed to measure the lower self, may not reflect the awakening to a transpersonal plane of functioning that follows an NDE.
\end{abstract}

The near-death experience is a constellation of altered-state phenomena often triggered by physiological emergency, similar in every respect to deep spiritual experiences. Although the near-death experi-

The author gratefully acknowledges the assistance of Dawn Schraeder and Gail Elkin, Senior Research Assistants at Harvard University, who scored Kohlberg's "Schedule A" instrument and Loevinger's Ego Development Scale, respectively; of James Fowler, Ph.D., of Emory University, who scored Fowler's Faith Development Scale; and of William Linson, M.D., of Southern Pines, NC, who evaluated the Life Interview transcripts.

Dr. Newsome is in the private practice of psychotherapy and counseling. This paper was derived in part from her Ph.D. thesis submitted to Walden University. Requests for reprints should be addressed to Dr. Newsome at P.O. Box 4774, Springfield, MA 01101-4774. 
ence (NDE) can be traced back through thousands of years in human history, in the modern era the phenomenon began to draw public attention only in 1975, with the work of psychiatrists Elisabeth Kübler-Ross and Raymond A. Moody, Jr.

During this first decade of investigation into near-death experiences, researchers uniformly reported the perception of individual experiencers that their basic value structures were profoundly altered as a result of the NDE. The experiencers commonly reported a strong shift toward intensified compassion and a sense of unconditional love; a lessening of materialism; increased spiritually; and a rising sense of mission to be of service to others.

Such accounts of dramatic attitudinal shifts have given rise to the theory that near-death experiencers may represent a new stage in human evolution, one that will produce major social change. As the number of NDEs increases throughout the world, it is hoped that the values commonly reported as part of the post-NDE transformation -including agape love and service to others-will take precedence over materialism and competitiveness, signaling the beginning of a new age of peace for humanity. Post-NDE attitudes in individual experiencers are believed by many to be so extensive as to signal a shift not only to a higher level of functioning, but perhaps even to a new evolutionary level and a species that John White has named Homo noeticus, precursor of the human future (Ring, 1984).

Throughout the near-death literature, these assertions of dramatic developmental change share a common and serious weakness: they are based entirely on experiencers' subjective reports, unverified by objective measures and unexplored in critical depth. The primary and most obvious reason for this lack is the near-impossibility of obtaining such objective data; secondarily, the number and scope of research studies is limited because the field of near-death studies is still in its infancy. In the absence of quantitative tests to measure the reported changes, case studies could provide initial information about these issues. However, no reported studies have examined individual experiencers in sufficient detail to substantiate whether they do, in fact, demonstrate high levels of ego, moral, and faith development in their attitudes or in their functioning.

\section{Literature Review}

Virtually the entire field of near-death studies has developed within the past ten years. With the exception of Moody's seminal Life After Life, published in 1975 , the major studies have appeared only since 
1980. The intent of the research during these first years has been essentially descriptive, establishing the near-death experience as a genuine phenomenon and tracing its principal elements. The study of aftereffects is now in its earliest stages.

While the number of researchers remains small and the content of published materials is still fully accessible, the needs of such a new area of study are easily observed. As the broad outlines of the subject have been identified, it is now possible to consider more intensive, qualitative studies incorporating standardized investigative instruments and more probing interviews. Moody's work is entirely anecdotal. He has never claimed otherwise. Life After Life and its companion volume, Reflections on Life After Life, published two years later, are a compilation of Moody's observations on and quotations from a group of 150 NDEs collected over a period of years surrounding Moody's graduate study at the University of Virginia. Moody identified the pattern of elements now accepted as defining the phenomenon and gave it the name "near-death experience." His intent was directly and simply to draw the experience to public attention, not to investigate it in depth. His phenomenal success in capturing international interest provided a foundation for the later work.

Social psychologist Kenneth Ring was the first to attempt a systematic study of the near-death phenomenon. His first book, Life at Death (1980), produced an abundance of demographic data about NDE population characteristics, the relative frequency of specific elements within the overall pattern, and the circumstances under which the events occurred.

In that first work, Ring summarized his findings on personality and value changes: "The things that [the experiencer] values are love and service to others; material comforts are no longer so important. He becomes more compassionate toward others, more able to accept them unconditionally. He has achieved a sense of what is important in life and strives to live in accordance with his understanding of what matters" (p. 158). Later he noted the "heightened inner religious feeling" (p. 162) that follows an NDE, adding, "My personal interaction with many core experiencers left me with the impression that a spiritual awakening had definitely occurred in a number of them" (p. 166). Ring himself has consistently noted the need for more systematic studies (pp. 22, 40, 258-260).

For his second study, published as Heading Toward Omega (1984), Ring developed three questionnaires to expand the available data about these reported personality and value changes. Two were to be completed by the interviewee, and the third by persons who had known the individual before the NDE. The study produced additional reports 
of profound and lasting change in values, attitudes, and behaviors. Further, the questionnaires did provide better data than the unstructured individual reports that had existed previously; the effort to obtain third-party observations was especially useful. Ring was able to state that "we can tentatively conclude that there is no indication whatever that the self-reports of NDErs are biased or in any way invalid" (1984, p. 141).

Based on the shifts in value structures reported to him, Ring suggested far-reaching implications for social change. The NDE, he wrote, may represent "an evolutionary thrust toward higher consciousness" (1984, p. 255). Ring also asked, "Are we seeing in such people-as they mutate from their pre-NDE personalities into more loving and compassionate individuals - the prototype of a new, more advanced strain of the human species striving to come into manifestation?" (1984, pp. 254-255).

Following Ring's Life at Death by two years, the second research work to appear was cardiologist Michael B. Sabom's careful Recollections of Death (1982). Sabom's interest was to substantiate the existence of the NDE as a genuine phenomenon and to suggest implications for change in medical practice, not to document long term aftereffects or shifts in personality or values.

Nevertheless, Sabom and his social worker associate, Sarah Kreutziger, used both the Templer Death Anxiety Scale and the Dickstein Death Concern Scale to assess post-NDE fear of death, which had been frequently reported as lessening following the experience. Their findings corroborated the reports that fear of death decreases after a neardeath experience (pp. 125, 213).

With his interest in post-NDE value changes piqued by the work of Moody and Ring, sociologist Charles Flynn investigated the beliefs, values, and social commitments of a group of 21 near-death experiencers (1986). His results strongly supported the contention that the NDE produces deepened concern for others; a denial of materialism as the source of meaning; heightened spirituality and religious understanding; lessened fear of death; and an emphasis on unconditionally loving relationships with humanity as a whole, as well as with significant others (p. 166). Flynn's findings were drawn exclusively from the voluntary comments of his subjects.

A 1985 bibliography prepared by psychiatrist-researcher Bruce Greyson (personal communication, 1985) listed all articles on neardeath and related subjects that had appeared in professional journals and general periodicals through that year. Although the list ran to 53 pages, the sole article dealing with NDE aftereffects and/or beliefs was 
an early report by Flynn based on an aggregate of experiencer opinion that their values had, indeed, changed since the NDE.

The literature on near-death experiences clearly shows the conviction of many experiencers and researchers that the event produces significant leaps in universalized faith, sense of self and world (i.e., ego development), and moral values. Ring's work, in particular, has been widely influential in shaping the public view of near-death experiences as transformative.

Despite the near-unanimity of this belief among experiencers, researchers, and the public, the literature on near-death experiences has, in its early years, been too focused on demographics and initial description to probe deeply into these issues through case studies and the use of validated instruments.

The pursuit of these questions is essential to building a more solid base for our understanding of the near-death experience in particular and of the nature of human consciousness in general. A deeply probing exploration into these questions constitutes a needed step in the development of near-death studies as a scholarly discipline.

\section{Theoretical Framework}

The use of hierarchical and qualitative imagery is common in the literature of near-death and other spiritual experiences. Stage theorists also employ concepts of hierarchy and quality to describe developmental change. In both cases, "higher," which is believed to represent "more developed," becomes almost invariably equated with "better." This similarity of linguistic and conceptual usage provides the basis for examining the developmental status of near-death experiencers by the standards of three major stage theorists.

\section{Hierarchy and Quality in Near-Death Literature}

Illustrating a viewpoint typical of near-death experiencers, a Canadian businessman described his NDE as movement into "a state that existed of nothing more than consciousness, but what a sublime consciousness it was! It was like a rebirth into another, higher kind of life" (IANDS Archives). Similarly, Ring has cited Gopi Krishna's conviction that "one who has attained to a higher state of consciousness ... should be characterized by four exceptional attributes, namely, genius, psychic talents, lofty traits of character, and an expanded state 
of consciousness" (1984, p. 170). As Huston Smith has noted, "the Good dons metaphors of height. Mountains are sacred and the gods dwell in the heavens" (1876, p. 21).

Ring's own view of the NDE in Heading Toward Omega was that it constitutes an evolutionary mechanism that provides a kind of "onward and upward" boost to individual experiencers, pointing ultimately to social change through transformation of the human species. In the same vein, Ken Wilber has noted that "at all stages of past human history, certain highly advanced individuals managed to evolve considerably beyond their fellows and into aspects of the higher realms themselves (the superconscious realms). These were the prophets, the saints, the sages, the shamans, the souls who, as the growing tip of human consciousness, discovered the higher levels of being through an expansion and precocious evolution of their own consciousness" $(1981$, p. 10$)$.

In precisely these "higher levels" Ring located near-death experiencers with their hints of social change, the persons who "may in some way prefigure our own planetary destiny, the next stage of human evolution, the dazzling ascent toward Omega and the conscious reunion with the Divine" (1984, p. 269).

\section{Hierarchy and Quality in Developmental Stage Theory}

According to hierarchical stage theory, cognitive development is characterized by qualitative changes in cognitive structures. Jean Piaget's work, the foundation of stage theory, also presents development as a phenomenon not only of process over time, but also, in its qualitative aspects, of increasing worth. In this regard, Jane Loevinger has said of Piaget that "he focuses on those action patterns ... from which the universal characteristics of things, or at least of physical things, derive-for example, extension in space, mobility and reversibility in space and time, and permanence. The explanation for the universality of Piagetian sequences lies here, and not in any geneticmaturational mechanisms" (1976, p. 42).

Both developmental stage theory and the transformative interpretation of near-death experiences, then, carry a simultaneous sense of time and an expectation of increasing quality, a shared anticipation of "onward and upward" movement. This theoretical line represents $\mathrm{Pi}$ aget's concept of "structured wholeness."

Lawrence Kohlberg has defined structured wholeness as "a conception of underlying thought organization that determines responses to 
tasks that are not manifestly similar. . . The general empirical implication of this conception is that individuals' thinking will be manifested at a single, dominant stage when observed across instances of varying content" (1984, p. 15).

Behind all this is the structuralists' position on development itself. Human processes-in this case, cognition, ego, and personality-are viewed as composed of parts constituting an ordered whole. The elements of thought, belief, and aware self are not random and disordered, but consist of a set of relations among the parts or elements. These relations define structure as a set of laws independent of the parts. Augusto Blasi defined this view: "Development consists of the acquisition or change of the basic rules governing the relations among the elements" (1976, p. 31).

For the average near-death experiencer, then, according to the literature, the basic rules will have shifted suddenly and explosively, calling forth a rapid developmental surge. Whatever the individual's developmental level may have been prior to the NDE, the viewpoint of both near-death and stage theory literature leads one to expect that the experiencer's present developmental status will be in the qualitatively higher and assumedly more adequate stages.

The theoretical basis for the present study thus lies in the original work of Piaget, as developed by the stage theorists Kohlberg, Loevinger, and James W. Fowler. Their work has been chosen specifically because of its alignment with the essential axis-or, to include the physical laws of motion, the trajectory-of NDE effects as described by Ring and others, including near-death experiencers themselves. To one degree or another, all of these-developmental theories and beliefs about NDE traits-may be said to represent expressions of a hope that as human individuals change and grow, transformation may be seen not only in their lives but in human society also.

\section{Social Change}

Whether viewing social change as linear progress or cyclical variance, as disequilibrium destabilizing a system or orderly process within a stabilized system (Parsons, 1951, p. 535), one can hardly dispute that we live at the brink of something new.

"A new paradigm," wrote George B. Leonard, "appears and prevails only if the old one is in a state of crisis" $(1972, p$. 122). The number of commentaries on the crisis in Western society is legion, with the work of Alvin Toffler (1970), John Naisbitt (1982), and Marilyn Ferguson 
(1980) perhaps among the best known. Although the fact of massive change in our time is undisputed, no single theory of social change holds primacy. Each theory may hold a significant piece of the puzzle, but none has captured the entire picture.

In 1970, Toffler published his now-classic description of the rapidity of at least one precipitant of social change:

It has been observed ... that if the last 50,000 years of man's existence were divided into lifetimes of approximately sixty-two years each, there have been about 800 such lifetimes. Of these 800 , fully 650 were spent in caves.

Only during the last seventy lifetimes has it been possible to communicate effectively from one lifetime to another-as writing made it possible to do. Only during the last six lifetimes did masses of men ever see a printed word. Only during the last four has it been possible to measure time with any precision. Only in the last two has anyone anywhere used an electric motor. And the overwhelming majority of all the material goods we use in daily life today have been developed within the present, the 800th, lifetime. (pp. 13-14).

While pragmatists note the social change produced by the generalized impact of proliferating technologies, and theorists debate the relative contributions of cultural structure and function or differentiation and integration, still another, smaller, group-not always from the discipline of sociology - has in recent decades begun to speculate on social change from a perspective of less easily observable, quantifiable factors. They are looking at shifting human consciousness and spirituality.

Their perspective has been supported strongly by the Jesuit paleontologist Pierre Teilhard de Chardin, who said in a 1945 lecture:

The higher the degree of complexity in a living creature, the higher its consciousness. ... So it comes to this, that when we have reached the point where complexity can no longer be reckoned in number of atoms we can nevertheless continue to measure it ... by noting the increase of consciousness in the living creature-in practical terms, the development of its nervous system. . . [We may posit] that ahead of, or rather in the heart of, a universe prolonged along its axis of complexity, there exists a divine center of convergence. . . . Let us call it the Point Omega. Let us suppose that from this universal center, this Omega point, there constantly emanate radiations hitherto only perceptible to those persons whom we call "mystics." Let us further imagine that, as the sensibility or response to mysticism of the human race increases ... the awareness of Omega becomes so widespread as to wary the earth psychically while physically it is growing cold. Is it not conceivable that Mankind, at the end of its totalisation, its folding-in upon itself, may reach a critical level of maturity where, leav- 
ing Earth and stars to lapse slowly back into the dwindling mass of primordial energy, it will detach itself from this planet and join the one true, irreversible essence of things, the Omega point? (1964, pp. 116-126)

Ring's major speculations about the evolutionary significance of the near-death experience, or of NDEs collectively, derive from Teilhard de Chardin's thought and have been discussed in Ring's second book, Heading Toward Omega (1984).

\section{The Theorists: Kohlberg, Fowler, Loevinger}

The three theorists whose work provides the primary underpinning of this study share with Piaget the view that structure-the organization of principles underlying specific beliefs or functions-is the principal determinant of developmental level. In other words, attained patterns of thought or personality development rather than content have the greater relevance; the question in determining stage level is less what is expressed than why and how it is expressed. To use Kohlberg's own words, structuralists "distinguish between the content [of thinking] ... and its structure or form.... [They focus] on the form of thinking rather than the content because it is the form that exhibits developmental regularity and generalizability within and across individuals" $(1984$, p. 38$)$.

Similarly, Loevinger had originally expected to find, in her test groups, observable differences in content at different levels. She discovered, however, that the same things were often discussed across levels, but with shifts of interpretation and emphasis (1976, p. 232). Her exploration of ego development acknowledges content as a partial determinant, but she remains essentially a structuralist.

Of the three, Loevinger's work encompasses the widest scope-the development of ego, envisioned as more than simply cognitive-but is least well known, while Fowler's, the most specialized, has attracted a strong following. It is Kohlberg, though, always conceptually closest to Piaget, who in his work on the development of moral judgment or cognition established stage theory most firmly in this generation of researchers, and who has set the standard others will follow or rebel against.

\section{Kohlberg: Moral Development}

Like Piaget, Kohlberg limited his investigations to human development in an area with a strong cognitive base, specifically the mani- 
festation of growth of moral judgment. Basic to his work is the belief that "the study of moral development must consider the subject's own reasons and construction of moral meaning" rather than "attributing meaning to the judgments from some outside system of interpretation not shared by the subject" $(1984$, p. 2). His theory examines the individual's cognitive ability to assume perspectives other than his or her own as the basis for solving moral dilemmas; increasingly inclusive roletaking becomes the measure of development. Over twenty years of investigation, Kohlberg has identified four levels in the development of moral judgment; they encompass six defined stages and a possible seventh.

From the earliest literal, egocentric stage in which authority is perceived as external and moral judgment derives from a fear of punishment, individuals mature through levels of increasing perspectivetaking toward principled thought. In the model presented by Kohlberg, "higher stages displace (or rather reintegrate) the structures found at lower stages. Formal operational thought includes all the structural features of concrete operational thought, but a new level of organization. Concrete operational thought or even sensorimotor thought does not disappear when formal thought arises, but continues to be used in concrete situations where it is adequate ..." (Conn, 1986, p. 72). However, as their limitations appear, the earlier stages are discarded as insufficient and restrictive.

Among adults, the norm is represented by the second level, which includes Stages 3 and 4, in which group and societal affiliations are paramount and in which interpersonal relationships take precedence over egocentrism. The move to this level from the radically egocentric orientation represents a major shift from a premoral to a moral stage; that is, it enables a distinction between "worth-for-me" and "worth" for its broader sake as a criterion for decision-making.

The individual moving into Stage 3, the Conventional, is moving from self-interest to social concern, from the expectation of exact exchange to "the Golden Rule ideal of imaginative reciprocity" (Kohlberg, p. 149). Community and kinship set the boundaries for Stage 3 moral judgment, and will be looked to for both guidance and support. Decision-making at this stage will be based on maintaining good relations within the group and therefore on a desire for its approval.

At the same level but the next stage, entrance to Stage 4 carries the individual into concern for the basic rights underlying group-specific values, with increasing emphasis on the system and one's responsibility to it, that is, conscience. Justice, as principle, now operates not only between individuals but stands as a matter of taking one's place 
in society, of equity and balance across groups. For Stage 4, the basis for morality is the principle of law and order.

More advanced stages of moral judgment are demonstrated by a sense of social contract and the greater good of the community and, finally, by appeal to universal principles of justice. The primary shift to Stage 5 requires rooting moral reasoning not in the "givens" of conventional values (external), but in the development of one's own sense of underlying principle, rooting "the final criterion of value in one's own critical judgment, thereby [becoming] the author of one's own moral life" (Conn, 1986, p. 29). Authority now lies not "beyond," in external centers, but within; paradoxically, as the self assumes authority, one's concerns become more broadly focused, going more beyond the self's narrow interests toward ever greater and wider inclusiveness. In the moral judgment of a person at Stage 5, "laws should be made by constitutional contractual procedures in order to maximize the welfare of all, and laws should be obeyed as part of the contract of a citizen with society" (Kohlberg, 1981, p. 157). The basis for morality at Stage 5 is therefore considered to be democratic contract.

Stage 6 morality is based on individual principles of conscience. In his early work, Kohlberg postulated that at Stage 6 individuals would have moved into a universalized, prescriptive system of moral judgment organized around a "clearly formulated moral principle of justice and respect for persons" that would provide a rationale for that principle. However, in 1984 Kohlberg wrote, "Stage 6 has disappeared as a commonly identifiable form of moral reasoning as . . . none of our longitudinal subjects in the United States, Israel, or Turkey has attained it" (p. 270). For practical purposes at the present time, Stage 6 might be considered reserved for the saints and sages referred to by Wilber, those identified by Kohlberg as including only the greatest and rarest of moral exemplars-such individuals as Jesus, Martin Luther King, and Mohammed.

Without exception, individuals at Stage 6 constitute an elite not only in their commitment to moral leadership, but in their formal philosophic training (which even he admits may explain why none of his own subjects could be considered to have reached it). Each of them came to maturity from within a disciplined system of belief and moral principle, the observance of which came to take precedence over every other value. However much Stage 6 persons renounce the literal content of their belief system (i.e., Jesus' rejection of slavish adherence to the Law), they appear to move closer to its structure and spirit (Jesus' insistence on mercy and justice as divinely derived).

Stages 1 through 5 can derive from rational, human origins; with 
Stage 6, however, "universal ethical principles cannot be as immediately justified by the realities of the human social order. Such a morality uniquely 'requires' an ultimate stage of religious orientation and moves people toward it" (Kohlberg, 1981, p. 344).

In the even more rarified-and perhaps metaphorical-air of Stage 7, Kohlberg postulated, the individual would have arrived at a level of absolute autonomy. At this level, the question "Why be moral?" cannot be resolved by an appeal to reason or logic, but must be resolved by identifying the self with "the cosmic or infinite perspective itself" (1981, p. 344). Kohlberg called this the stage of "Cosmic Law, Agape Orientation." Because so much of the dialogue with near-death experiencers reverberates with similar references, it has given rise to the expectation that they may now operate from the highest levels of moral judgment and principled action, beyond reason and logic and beyond the concerns of the human social order.

\section{Fowler: Stages of Faith}

As Fowler described it, faith is a knowing, a construing, or an interpreting of experience in light of a person's (or a community's) relatedness to those "sources of power and values which impinge on life in a manner not subject to personal control" (Conn, 1986, p. 45). By faith, Fowler meant an individual's orientation to the "ultimate environment" in terms of what is valued as being most relevant and important to his or her life.

So interpreted, faith is tacit and universal; it may appear in various forms, from thoroughgoing secularism (the ultimate environment understood as nihilistic or mechanistic) to religion in its more particular, explicit expressions of faith. Faith, wrote Fowler, "is response to action and being that precedes and transcends us and our kind; faith is the forming of images of and relation to that which exerts qualitatively different initiatives in our lives than those that occur in strictly human relations" (1981, p. 33). This "faithing," to use its process sense, is a universal human construct involving the total self-cognitive, affective, and evaluative aspects woven together inextricably. It is both evolutionary in the way it imagines and revolutionary in its centering; the former deals with development, the latter with conversion.

In his analysis of the stages of faith, Fowler, like the other structuralists, looks at the structure underlying this "faithing," focusing on "the patterned process of knowing and valuing rather than on the content of faith as knowledge and values" (Conn, 1986, p. 45). The 
criterion for development, in Fowler's theory, is self-transcendence, moving beyond one's present stage to the more complex and inclusive "beyond."

The stages of faith outlined by Fowler broadly parallel Piaget's stages of cognitive development and, correspondingly, Kohlberg's stages of moral judgment. Following the undifferentiated state of infancy comes the "Intuitive-Projective" Stage 1 of faith, typical of the three-to-seven age group. Here, at the stage when self-awareness first emerges, is "the fantasy-filled, imitative phase in which the child can be powerfully and permanently influence by examples, moods, actions and stories of the visible faith of primally related adults" (Fowler, 1981, p. 133). While the gift of this stage is the inception of imagination, the dangers rise from 'the possible 'possession' of the child's imagination by unrestrained images of terror and destruction, or from the ... exploitation of her or his imagination in the reinforcement of taboos and moral or doctrinal expectations" (Fowler, 1981, p. 134). Conversion to Stage 2 is precipitated by the onset of concrete operational thinking.

Stage 2 is the Mythic-Literal, characterized by the emergence of identification with community beliefs, stories, and ritual, and their literal interpretation. The making of meaning tends to be narrative, linear, anthropomorphic. While the gift of this stage is just that narrative ability, its attendant dangers can sometimes be seen in adults who maintain its excessive perfectionism or the sense of unremitting "badness" originating in perceived community disfavor. The conversion impetus, wrote Fowler, may be "the implicit clash or contradictions in stories that leads to reflection on meanings. The transition to formal operational thought makes such reflection possible and necessary" (Fowler, 1981, p. 150).

At Stage 3, that of Synthetic-Conventional Faith, comes "the formal operational ability to construct the hypothetical" (Fowler, 1981, p. 152). This stage is typical of most adolescents, but remains the "permanent place of equilibrium" (Fowler, 1981, p. 172) for many adults as well. It is more complexly social, no longer delimited by family boundaries. The key to Stage 3 is its interpersonal mandate, with the group the source both of the content of faith and of support for it. Specific beliefs are as yet unexamined in any deep sense; authority remains external to the individual.

Like Kohlberg, Fowler recognizes that to move beyond the adolescent social-dependent stance, one must achieve a cognitive conversion to being one's own authority. In Fowler's work, this first emerges in the transition from Synthetic-Conventional faith to the Stage 4 
Individuative-Reflexive faith, often precipitated by dramatic shifts in policy or practice on the part of formerly trusted authority or personal experiences strongly incongruent with the individual's background. Specifically or metaphorically, the transition to Stage 4 may involve "leaving home."

"For a genuine move to Stage 4 to occur," stated Fowler, "there must be an interruption of reliance on external sources of authority"-an objectifying of one's previous value system-and "a relocation of authority within the self" (Fowler, 1981, p. 179). Symbols will lose the immediacy of their relationship with the sacred, often deepening the sense of loss of certainty, of comfort, associated with Stage 3's unquestioning belief. Stage 4 is the question period, the time of the cry, "But what does it mean?" (Fowler, 1981. p. 180). The Stage 4 individual is more sensitive to the unique perspectives of other individuals, while developing-perhaps paradoxically-greater regard for social system, the shaper and regulator of law, custom, and standards.

Feelings of restlessness and disjointedness may propel a person from Stage 4 into Stage 5. Here, the neatness of the "knowns" breaks down; Fowler admits that Stage 5 baffles ease of description. At this stage, "the multiplex structure of the world is invited to disclose itself. ... The knower seeks to accommodate her or his knowing to the structure of that which is being known before imposing her or his own categories upon it" (Fowler, 1981, p. 185). Here, one comes to accept the reality of the unconscious as well as the conscious mind. The individual's own believed tradition or perspective is radically open to other truths, other claims, but with little need to "change camps" in order to participate in the truth of the other. At this stage, symbol and meaning can be reunited in a way deeper and more comprehensive than possible before. It is integrative, postcritical in a positive sense.

As with Kohlberg's Stage 6, Fowler's Stage 6 may be reserved only for the elect. (Here Fowler mentions Mohandas Gandhi, Thomas Merton, Dietrich Bonhoeffer, Abraham Heschel, and the later years of Martin Luther King, Jr.) He has said of this stage that its qualities will "shake our usual criteria of normalcy" (Fowler, 1981, p. 200).

Heedless of the threats to self, to primary groups, and to the institutional arrangements of the present order that are involved, Stage 6 becomes a disciplined, activist incarnation-a making real and tangible - of the imperatives of absolute love and justice of which Stage 5 has partial apprehensions. The self at Stage 6 engages in spending and being spent for the transformation of present reality in the direction of a transcendent actuality (Fowler, 1981, p. 200). 
One can say that Stage 6 actualizes the principles understood at Stage 5. Here the ultimate environment is recognized as universal and utterly inclusive, a unification of the whole of life and the self. The individual need not try to resolve paradox, but is able to move through it to personal transformation in an untransformed world.

\section{Loevinger: Stages of Ego Development}

Loevinger sees ego development as "the search for coherent meaning in experience" (Loevinger, 1976, p. 310), and, faithful to basic stage theory concept, traces it through invariant stages from infantile egocentrism through interpersonal levels and on to more sophisticated levels of postconventional thought. A moderate structuralist, she has, in fact, stated that "the only way to understand development consists in conceptualizing it as a sequence of structural changes" (Loevinger, 1976 , p. 51). In her view, however, ego development subsumes conceptual development, her most obvious variance from the hard structuralist view.

Cognitive structures, in Loevinger's theory, "represent systems of possibilities.... More adequate and developmentally more mature cognitive structures widen the range of possibilities, without moving from the domain of what is possible to the domain of what is, whereas in relation to cognition, personality is factual and determined" (Loevinger, 1976, p. 45). Cognition, it is stated, "does not offer the principle of determination, of preference, of value" (Loevinger, 1976, p. 43). This dim view of the ability of cognition alone to mediate development relates to Loevinger's conviction that rigorous structuralism is antihumanistic because it denies the possibility of human freedom and the role of consciousness.

Loevinger's aim has been to identify the pivotal meaning, the basic structure, of each stage, isolated from demographic and cultural factors. Concerned with qualitative changes in ego development, she creates a description of ego development both semantic and ontological. "The striving to master, to integrate, to make sense of experience is not one ego function among many but the essence of the ego" (Loevinger, 1976, p. 59).

Perhaps because of her association with Kohlberg, Loevinger's emphasis on moral factors produces a view of ego that is much like conscience (Conn, 1986, p. 309). Shifting away from Kohlberg, how- 
ever, her work demonstrates the conviction that as a person attempts to translate moral judgment into action "the criteria that an individual resorts to . . cannot be strictly formal but must refer to the content of his personality" (Loevinger, 1976, p. 44).

Yet she is adamant that ego development, though unqualifiedly real, is an abstraction not directly observable. "The ego is above all a process, not a thing. The ego is in a way like a gyroscope, whose upright position is maintained by its rotation. ..." (Loevinger, 1976, p. 58). Ego development, then, will be very much an achievement of relative stability attained by a being-in-motion.

Maturation, in this view, occurs simultaneously across four areas of ego development: impulse control/ character development; interpersonal style; conscious preoccupations; and cognitive style. However, Loevinger is quick to note the danger of interpreting these threads in the ego's "complexly interwoven fabric" as separate dimensions of ego development. "There is just one dimension. The four descriptive columns display four facets of a single coherent process" (Loevinger, 1976, p. 26). With this qualification, Loevinger echoes Piaget's idea of "structured wholeness" in her own more comprehensive approach to stage theory.

The most concise description of Loevinger's approach is her own:

The conception of ego development as a sequence of stages that also constitutes a set of personality types is necessarily an abstraction. The fundamental characteristics of the ego are that it is a process, a structure, social in origin, functioning as a whole, and guided by purpose and meaning. Development implies structural change, but the mechanistic philosophy of some structuralists forecloses our topic of study.... We acknowledge both consciousness and the possibility of freedom and the validity of the dynamic unconscious; so the ego is not the same as the whole personality. It is close to what the person thinks of as his self. (Loevinger, 1976, p. 67).

Because the sequence of stages in Loevinger's ego development theory so nearly parallels those of Kohlberg and Fowler, I will not offer them here in full narrative form. They appear in summary in Table 1, derived from Loevinger's Ego Development (1976).

\section{The Problem of Affect}

One can read the structuralists at great length and come away with the perception that all of life is thought and belief, that where cogni- 


\section{Table 1 \\ Loevinger's Stages}

\begin{tabular}{|c|c|c|c|}
\hline Stage & Code & $\begin{array}{c}\text { Impulse Controh } \\
\text { Character Development }\end{array}$ & Interpersonal Style \\
\hline Presocial & & & Autistic \\
\hline Symbiotic & $\mathrm{I}-1$ & & Symbiotic \\
\hline Impulsive & I-2 & $\begin{array}{l}\text { Impulsive; fear of } \\
\text { retaliation }\end{array}$ & $\begin{array}{l}\text { Receiving, dependent, } \\
\text { exploitative }\end{array}$ \\
\hline Self-protective & & $\begin{array}{l}\text { Fear of being caught, } \\
\text { externalizing blame, } \\
\text { opportunistic }\end{array}$ & $\begin{array}{l}\text { Wary, manipulative, } \\
\text { exploitative }\end{array}$ \\
\hline Conformist & $\mathrm{I}-3$ & $\begin{array}{l}\text { Conformity to external } \\
\text { rules, shame, guilt for } \\
\text { breaking rules }\end{array}$ & $\begin{array}{l}\text { Belonging, superficial } \\
\text { niceness }\end{array}$ \\
\hline $\begin{array}{l}\text { Conscientious- } \\
\text { Conformist }\end{array}$ & I-3-4 & $\begin{array}{l}\text { Differentiation of norms, } \\
\text { goals }\end{array}$ & $\begin{array}{l}\text { Aware of self in relation } \\
\text { to group, helping }\end{array}$ \\
\hline Conscientious & $\mathrm{I}-4$ & $\begin{array}{l}\text { Self-evaluated standards, } \\
\text { self-criticism, guilt for } \\
\text { consequences, long-term } \\
\text { goals and ideals }\end{array}$ & $\begin{array}{l}\text { Intensive, responsible, } \\
\text { mutual, concern for } \\
\text { communication }\end{array}$ \\
\hline Individualistic & I-4-5 & $\begin{array}{l}\text { Above, plus respect for } \\
\text { individuality }\end{array}$ & $\begin{array}{l}\text { Above, plus dependence } \\
\text { as an emotional problem }\end{array}$ \\
\hline Autonomous & I-5 & $\begin{array}{l}\text { Above, plus coping with } \\
\text { conflicting inner needs, } \\
\text { toleration }\end{array}$ & $\begin{array}{l}\text { Above, plus respect for } \\
\text { autonomy, } \\
\text { interdependence }\end{array}$ \\
\hline Integrated & $\mathrm{I}-6$ & $\begin{array}{l}\text { Above, plus reconciling } \\
\text { inner conflicts, } \\
\text { renunciation of } \\
\text { unattainable }\end{array}$ & $\begin{array}{l}\text { Above, plus cherishing of } \\
\text { individuality }\end{array}$ \\
\hline
\end{tabular}

tive process prevails, the untidiness of emotion can be eliminated. This is unfair, to be sure, but the perception remains.

Kohlberg has been called a "moral rationalist" (Conn, 1986, p. 25). While not excluding the importance of affect entirely-for the increasing role-taking that determines development for him is the exercise of empathy-he tends to assign it a role contingent and dependent upon moral judgment; his references are more typically to guilt and fear than to joy and tenderness. Fowler has summarized the dilemma exactly:

As one examines [the study variables] reflectively, it may seem that the dynamic which lies at the heart of faith-namely, a centering 
affection, an organizing love, a central object of loyalty and trust-is missing. And this is true. To note this is to be reminded again of the formal and structural focus of this stage theory. It is this formal character which gives the theory the possibility of being applied to a variety of different religious traditions with a variety of contents as regards prescribed beliefs, values, attitudes and behaviors. (Conn, 1986, p. 134.)

\section{Purpose and Implications of Study}

My intent is to provide in-depth case studies in the emerging field of near-death research. I will examine relationships between three experiencers' tested levels of moral, ego, and faith development and the extensive qualitative data gathered from their NDE accounts and intensive interviews. I hope that clarifying the specific developmental levels of near-death experiencers will encourage efforts already underway in several disciplines to foster improved understanding of human consciousness and social value structures.

Among health care providers, counseling therapists, clergy, and the general public, concern for experiencers' efforts to integrate the NDE has risen sharply; the fresh insights from this study are expected to strengthen current professional understandings of and therapeutic approaches to experiencers who come for help. Of particular interest to myself and other therapists is the potential for developing training modules for counseling professionals. At present, the absence of accessible, solidly grounded data about how best to assist clients who have had deep spiritual events limits most therapists to the medical/ pathological model. Inappropriate counselor responses and misguided interventions are a frequent result, leading to profound and often counter-productive frustration in therapist and client alike (Greyson \& Harris, 1987). The prospect of strengthening quality of care can be addressed only with data such as those sought by this study.

In the area of social change, exploration of individual experiences of profound insight may provide a fresh means of reexamining the bases on which we establish moral sociopolitical relationships. This could, in turn, strengthen the argument that cooperation and caring are as basic human drives as territorial imperatives. Related to this, support for Ring's and others' findings about the transformative social potential of the NDE is expected to enhance the credibility of the field of near-death studies among academic researchers who have been slow to consider this a legitimate field for scholarly work.

The results of this present study could further offer a substantive 
base for subsequent exploration of the correlation between the perceived values of near-death experiencers and behavioral variables i.e., the relationship between experiencers' developmental shifts at the cognitive level and their behavioral adaptations to such sudden stage changes.

\section{Methodology}

To explore whether the attitudes and values of a group of near-death experiencers are markedly advanced from the norm, I conducted intensive case studies of three near-death experiencers. The case studies are based on information derived from five interview protocols: (1) three stage-level questionnaires and depth interview protocols originated by Loevinger, Kohlberg, and Fowler; (2) a specially developed Newsome Protocol to probe additional belief and value dimensions: and (3) videotaped life interview. Additionally, participants were asked to make a spontaneous drawing of their near-death experiences.

\section{Sample}

The near-death experiencers whose case studies form the basis of this study were identified originally from the archives of the International Association for Near-Death Studies, Inc. (IANDS), located at the University of Connecticut.

Two of the criteria for selection were considered primary: (1) that the individual's near-death experience have occurred not less than seven years ago, to allow time for integration (Atwater, 1988); and (b) that the NDE itself have been of moderate to deep intensity according to the standards of Ring's Weighted Core Experience Index (Ring, 1980).

Secondary criteria for sample selection were (a) residence within a two-hour driving distance from the University of Connecticut; (b) a willingness to participate as a subject in the study; and (c) the practical ability to volunteer for a minimum of four meetings requiring at least twelve hours of interview and testing time per person. Five persons identified as meeting all these requirements constituted the original sample. Two dropped out as the study progressed, citing time constraints and personal reasons.

The small sample size necessitated by the intensity of the investigation has the advantage of providing an abundance of qualitative information of a type not previously gathered in this field. 


\section{Weighted Core Experience Index}

Ring's Weighted Core Experience Index (WCEI) was used as a standard scale for substantiating a near-death experience. Using ten common components of the NDE as identified by Moody and corroborated by his own study, Ring weighted the items in accordance with their apparent relevance to depth of experience. Scores can range from a theoretical low of 0 to 29, representing the deepest Moody-type experience (Ring, 1980).

Participants in the present study had WCEI scores greater than 9 , indicating a deep experience. Written accounts of the participants' experiences were scored for WCEI ratings by the IANDS archivist.

Frank S. (subjects' names have been changed for purposes of confidentiality) received a WCEI score of 11: 1 point for a sense of being dead, 4 for the core affective cluster (feelings of peace, painlessness, pleasantness, etc.), 2 for being enveloped in light, and 4 for entering into the light. Alice $D$. received a WCEI score of 10:4 points for the core affective cluster, 3 for taking stock of her life, and 3 for encountering visible "spirits." Paul W. also received a WCEI score of 10: 4 points for the core affective cluster, 2 for a sense of bodily separation, 3 for encountering a presence or hearing a voice, and 1 for seeing colors.

\section{Interviews}

Each participant was interviewed at least four times over a period of a year. Most meetings were in participants' homes, although one person was interviewed in his office. Each session was audiotaped with the exception of the Life Interview, which was videotaped.

Interview \#1. The purpose of the first meeting's opening segment was primarily to establish a relationship, to explain the purpose of the study in general and obtain consent forms, and to answer any questions. This part of the interview averaged one hour.

The second segment introduced the first instruments. Because it is brief and easy to administer, Loevinger's Ego Development Scale was given first. This sentence-completion questionnaire of 36 items was accomplished in sittings ranging from 30 to 90 minutes, depending primarily on the complexity of the responses.

Interview \#2. At the second interview, the Kohlberg "Schedule A" instrument of four dilemmas was administered, with a fifth added for additional depth of information. Kohlberg's scale is presented as a 
series of structured dilemmas requiring the use of moral judgment. The interviewer is instructed to listen patiently, restating questions if the participant does not want to answer a dilemma as given, keeping the situation comfortable, yet persisting to get the actual questions answered. The dilemmas were presented verbally, taking from one to three hours of time.

Interview \#3. Fowler's Faith Development Scale was the third interview instrument. Designed as a series of open-ended questions about the individual's life experiences and beliefs, it theoretically requires between one and two hours of administration time; however, in actual experience the Fowler interviews ran as long as four hours.

Interview \#4. Newsome Protocol. As indicated in the "Theoretical Framework" section, the three theorists on whose work this study depends tend to focus more on cognition than on affect. I designed the Newsome Protocol to explore more deeply the participants' feelings about and attitudes toward specific issues relevant to the study content but not addressed by Loevinger, Kohlberg, or Fowler. The Newsome Protocol required an interview ranging from two to three hours, taped and later transcribed.

Interview \#5. The final interview dealt with the individual's family background, upbringing, health, religious training, education, memorable incidents, and current life status. Each interview session was videotaped for inclusion as part of the data for this study.

\section{Drawing}

At the end of the life interview, each participant was offered paper and a box of colored markers, and invited to make a drawing symbolic of the near-death experience.

\section{Data Analysis}

\section{Stage Theory Instruments}

The three stage-level instruments were administered orally, audiotaped, and then transcribed. Blind copies of the transcriptions were sent to Harvard University for scoring by the senior research assistants of Loevinger and Kohlberg, and to Emory University for scoring 
by Fowler. Each scorer was asked to note key words and phrases significant in identifying the stage levels and to comment on any striking characteristics in the sample group's responses. These comments provided a means of more closely marking features that may be significant to the study's findings, and gave a base of expert opinion against which to examine the responses.

\section{Newsome Protocol}

I reviewed the Newsome Protocol responses for whatever additional light they could shed on the experiencers' feelings and beliefs in three principal areas: a) their beliefs in and about God, including God's gender; $b$ ) their understanding of the relationship between their physical lives (i.e., their bodies) and their spiritual lives; and c) their perceptions of personal changes since the NDE. More subjective than the scoring of stage-theory instruments, this review helped to clarify participants' attitudes about their present interior life.

\section{Life Interview}

The Life Interview was examined by the investigator and a Boardcertified psychiatrist for evidence of strikingly unusual life situations or expressions of psychopathology. It also provided an abundance of insights into the ways in which these three near-death experiencers have manifested, if at all, the traits of unconditional love, lessened materialism, and service to others postulated in the near-death literature.

\section{Results}

\section{Stage Levels}

As scored at Harvard and Emory Universities, the developmental levels of the three participants reveal individual differences rather than uniformity. Kohlberg stage scores were for Frank, Stage 3/4; for Alice, Stage 3; and for Paul, Stage 4/5. Fowler stage scores were for Frank, 2.25; for Alice, 3.25; and for Paul, 5. Loevinger stage scores were for Frank, 3/4; for Alice, 3/4; and for Paul, 4. 
Frank. Frank's Kohlberg responses included characteristics of Stages 3 and 4: a member-of-society perspective, indicating acceptance of social conventions; concern about social approval; concern about loyalty to persons, groups, and authority; and concern about the welfare of others and society. Stage 3 is most efficiently represented by the Golden Rule; Stage 4, by concern for the institutions of society and for individual roles in relation to the system. Frank's responses indicate an individual functioning on Level II (Conventional), Stage $3 / 4$, a mixture of the Mutual Interpersonal Stage and the Social System and Conscience Stage.

Frank's Fowler responses were characteristic of Stage 2.25, in which the person takes on the stories, beliefs, and observances that symbolize belonging to the community, with a world view based on reciprocal justice. The strength of this stage is the development of a narrative construction of coherence and meaning. Possible limitations of this stage include an abasing sense of badness embraced because of mistreatment, neglect, or the apparent disfavor of significant others. In Fowler's assessment, Frank's responses represent a Stage 2.5 perspective, the Mythic-Literal.

Frank's Loevinger responses included characteristics of Stage 3/4, which may indicate transition from conformist to conscientious: in mature life, a stable position, probably the modal level for adults in our society. Differentiation of norms and goals may indicate growing awareness of oneself as not always living up to the idealized portrait set by social norms, but inner life still couched in banalities and vague "feelings." Conscious preoccupations include adjustment, problems reasons, and opportunities. Frank's $3 / 4$ scoring places him at Loevinger's Self-Aware level, indicating that although at "probably the modal level for adults in our society," he may be working toward transition to the conscientious perspective.

Alice. Alice's Kohlberg responses were characteristic of Stage 3, a member-of-society perspective: living up to what significant others expect of you; "being good," that is, having good motives, showing concern about others, keeping mutual relationships such as trust, loyalty, respect, and gratitude. Alice's responses indicate a Level II (Conventional), Stage 3 (Mutual Interpersonal) perspective.

Alice's Fowler responses showed characteristics of Stage 3.25, in which one structures the ultimate environment in interpersonal terms. Individuals at this stage are acutely tuned to expectations and judgments of others, do not have enough grasp on their own identity to construct and maintain an independent perspective. Their readiness 
for transition may precipitate clash with authority and critical reflection on the relativity of values. Alice's responses represent a Stage 3.25 , which may be the modal level for adults.

Alice's Loevinger responses were characteristic of Stage 3/4, as were Frank's.

Paul. Paul's Kohlberg responses included characteristics of Stages 4 and 5, a member-of-society perspective based on balance across groups. Such a view is now based on universal principles, the moral commitments or standards on which any good or just society must be based. A freely entered commitment to social obligations, Stage 5 is based on the greatest good for the greatest number. The underlying principle rooting the final criterion of value is one's own critical judgment. Paul's Level III/IV (Conventional/Principled) responses are appropriate to the Stage 4/5 transitional perspective of a person moving from Social System to Social Contract.

Paul's Fowler responses were characteristic of Stage 5, implying an awareness of a multiplex world structure and of the "wisdom" of seeing things as they are, with no need to order them according to prior categories. Individuals in this stage are self-authenticating, with an ability to go beyond ideological and identity bounds. They feel a partial sense of imperatives of absolute love and justice, and are caught between universalizing apprehensions and the need to preserve their own well-being.

Paul's Loevinger responses were characteristic of Stage 4: the major elements of the adult conscience are in place, including long term, selfevaluated goals and ideals, differentiated self-criticism, and a sense of responsibility; the internalization of rules, and a sense of oneself as the origin of one's own destiny. Such individuals measure achievement by their own standards, and view the broad social context with conceptual complexities.

\section{Newsome Protocol}

Three areas were of particular interest to the interviewer: the experiencers' beliefs in and about God, including God's gender; their understandings of the relationship between their physical, bodily lives and their spiritual lives; and their perceptions of personal changes since the NDE.

God. At least one other study (Ring, 1984) resulted in the finding that $100 \%$ of the sample of near-death experiencers stated a belief in 
the existence of God. Although the present study has produced similar results, the definition of "God" remains vague.

All three participants received religious instruction as children, Paul in a devoutly Methodist family, Frank and Alice in practicing Roman Catholic households. All reported childhood feelings of fear, guilt, and apprehension toward God lasting at least until the NDE. Both men are religiously active; Alice has married a Presbyterian minister but remains nonpracticing.

From the outset it was evident that the question of God's gender was viewed, at best, as irrelevant. Noting that he had previously assumed a male aspect for God, Frank stated flatly, "There's no such thing as male or female" in the NDE. Even more bluntly, Paul scoffed at the idea of gender: "I believe in God the Father, God the Mother, and God my Great Aunt Tillie." Alice struggled to imagine being in the presence of a gendered deity, but concluded, "I cannot give it a gender. It's an It." The absence of gender for the participants' conception of the Deity has no evident importance to the issue of belief.

When, at the beginning of this session, the interviewer said to Frank, "You thought the light was God," the response was swift to the point of abrupt: "I didn't say I thought, I said I knew. It was simply the feeling of love." How would he describe God to a little child? He would not describe him at all, but would put his understanding of God into action: "To show what God is would be simply to love that child."

Similarly, Paul's stated present understanding of God, while complex, comes from his being "more assured of the love." To a child he would say, "God is love. God surrounds you completely with perfect care, and though that may not always be obvious to you, it is there."

Alice, who describes herself as having been "pretty much agnostic before" the NDE, preferred to characterize "the something that is more than we are" as "Universal Intelligence." To a child, she would explain that "God is a power, a power within all of us to do the very best we can in whatever we want to do, to be as nice to other people and as helpful to other people as we can be without making ourselves unhappy or doing anything wrong."

Body and Spirit. To whatever extent the general population may associate their lives and beings with their physical bodies, these three people clearly perceive their true selves otherwise. His body is "my vehicle" to Frank, "on loan," and although he "should probably take better care of it," it seems now "rather archaic, a crude way to exist." Alice agrees, commenting that her body is "mine to take care of, not to destroy." Paul put it succinctly: "Myself and my body - they may not be 
the same." "Whatever is real in me," he continued, "is going to endure, and I may not always realize what the reality is, but real doesn't depend on my body. It may use my body, but it doesn't depend on it."

Personal Shifts. Although the absence of pretesting makes purported changes after an NDE a moot point, the question of experiencer perceptions of changes remains interesting. Consistency in such reported changes was a major factor leading to the present study, while the discovery of variability of responses might lead to new issues for future study.

Alice responded with greatest enthusiasm when asked whether she has noticed changes in herself since the NDE. She mentioned particularly discovering a high energy level, a willingness to take risks, such as standing up to her family and acting against their wishes, and a sense of purpose, and she said "I don't feel alone."

Twelve years after his experience, Paul was more cautious. Given the variables of maturation and events that have occurred since, he considers the NDE "part of a whole life agenda," refusing to credit it with special significance in terms of possible changes in his outward self. For Frank, the change he has observed may be more internal. He spoke only of his awareness that "the love that I brought back with me, the love that I feel, my love of life, is equaled by my frustration. . . . It's living, almost, a dichotomy, and it can be frustrating, very frustrating."

\section{Life Interview}

The wide-ranging Life Interviews revealed no indications of psychopathology in any of the three people participating in the study. All are articulate and well-spoken, married, working at careers with apparent success, and functioning well within the range of normalcy.

Two common features of their childhoods seem to have been the strong impact made by older family members, especially grandparents, and an apparent sense of differentness or aloneness before puberty. Frank reports the least familial stress of the three childhoods, with both Paul and Alice reporting severe conflict originating in health issues and family disharmonies; the extreme disruption of Paul's adolescence by the emergence of his epilepsy and depression, and the discontinuous care experienced by Alice, coupled with her perception of paternal abusiveness, remain painful issues for them both. However, there appear to be no specific grounds in their narratives to lead 
one to attribute the occurrence of the later NDE to the personal history, although at least in Alice's experience her personal background and NDE content visibly related. No particular conclusions extending beyond these three people are warranted on the basis of these observations, which may represent simply coincidence in a small sample.

\section{Conclusions}

This study offers a view of the developmental level of three persons who have reported near-death experiences. However, a unique quality in experiencer affect and expression remains to be explored.

In saying that, I suggest two further things: first, that although the instruments developed to measure stage levels appear to serve well in "everyday" situations-i.e., situations that are amenable to cognitive expression-there is some evidence that they are not sensitive to subtleties of higher-level expression. Secondly, the tantalizing questions that rise from this study have rich implications for future research.

Among the most elusive elements of this investigation has been the effort to determine exactly what it is that gives these near-death experiencers a special, though intangible, quality. All three participants appear to share a sense of "knowing something."

Such perplexity strongly suggests that Kohlberg's scale and rating system may be incapable of capturing some information originating in spiritual premises and spiritual logic. Paul's responses, and quite possibly other people's, might indicate another category of "relational" rather than formal logic as the basis for decision making, as Carol Gilligan (1982) has argued is the case with women. Kohlberg himself noted the absence of Stage 6 level persons in his longitudinal studies in Israel, Turkey, and the United States. He was quoted above as having observed that at Stage 6, "universal moral principles cannot be as immediately justified by the realities of the human social order. Such a morality uniquely 'requires' an ultimate stage of religious orientation and moves people toward it."

The level of development measured by the three instruments may not offer a valid understanding of the experiencers' true development. High scores on these three ego measures may not be a measure of maturity, since true development may encompass more than development of the ego. The content of love may be the most important variable of concern in the development of the human species, and maybe even the only one. 


\section{Spirituality and Love}

The NDE seems to exemplify the totality of love. "Maybe the NDE is a message: Time to stop dissecting things and take life for what it is. Just simply learn to love and care and practice to share it," said Frank.

Human beings are meaning-making beings. Our egos demand order. In fact, all of the instruments used in this study were devised to dissect the human. We attempt to categorize the individual into compartments of development and create something that has meaning to society. The instruments, rather than helping us to accept each individual as a loving and grace-full and perfect being, seem to look only at the ego and define it as the "self." The ego is the organization of personality. Personality, in turn, is often seen as the entire being. The conscious self experiences itself as an entity with certain characteristics, views, and mechanisms of defense, all of which seem designed to maintain self-esteem. NDEs appear to cause a shift in perception, allowing experiencers to reach a realm of existence that is out of the realm of space and time, simultaneously real (i.e., solid) and spiritual, nonphysical and total. As the shift into the spiritual dimension occurs, the body becomes diminished into the lower self. In this way it becomes possible to differentiate between the lower and the higher self, with the lower self having to do with attitudes, personality traits, and desires that are organized around the needs, appetites, and desires of the physical being.

"I know," said Frank, "what it's like to be without it, and am very aware of the fact that I didn't need it. ... I thought of my body as being rather archaic, a crude way to exist. It's really an 'on loan' kind of thing." Once Frank became aware of his higher self, the shift occurred that moved Frank's awareness away from his behavior and transferred it to his identity.

In terms of the lower self, the ego is connected with what we fear and what we desire. Separation from the ego, therefore, is separation from fear. As the NDEr separates from ego, the fear is replaced by total peace. When the ego is functioning fully, we hold onto it and are afraid to lose it. The desires of the conscious self perpetuate along with the fears.

The Kohlberg, Fowler, and Loevinger instruments are designed to measure the lower self, the conscious experience of who one is and what one thinks. From a spiritual perspective, that would not be the true self. It would instead be how the person is as influenced by the conscious mind, which is in turn influenced by society, which is in turn influenced by the interpersonal plane of functioning. NDErs seem to 
have awakened and made a transitional step in contacting, or being contacted by, the higher self. When this happens, the source of an individual's values and motivations is no longer primarily the conscious self or the ego.

Frank, after his NDE, said that "It was almost like being born again. Nothing was the same, nothing has ever been the same. The importance to me of the whole experience, if I brought anything back at all, would be the importance of loving here on earth." There is a very clear value system here, and although life's "toys" are enjoyable to him, Frank lives his life more unattached to objects; he loves life rather than the objects it holds. He experienced the soul of nature, feeling God's essence in the world as a kind of vitality, or life force, a feeling of contact with a mystery, a life behind life, an awakening to realize the experience of God-equals-everything-everywhere.

Frank said, "The experience, for me, is characterized by the light. OK! The light being God, being love, being everything." He went on to discuss being one with the light, being one with everyone, being one with God and seeing God in everyone else. To see that God is everywhere is to allow ease; it creates a compatibility with the rest of the planet and with the rest of the universe. Once you experience this your life manifests itself on a different level. The impact that this knowledge/experience has on people is indescribable. The entire motivational basis of the individual is changed. This was documented in Ring's Heading Toward Omega (1984).

In addition to changing individuals' motivational patterns, the NDE causes all of the smaller desires and attachments to be perceived in a new way. The individual's entire orientation is changed in order to allow the discovery of what truly is.

The NDErs who had the experience of all-embracing love now experience life as meaningful in terms of love and in terms of what they can give to others. Some people experience this in Biblical terms. "The Way, the Truth, and the Light," said Paul, evidence that the transformation is produced through contact with the deepest level of truth and love; once you have touched God, anything less is not satisfactory as a life foundation. God said, "You are mine." NDErs seem to understand the idea of surrender to a higher calling. They function less from their egos, and letting go is no longer frightening. The conscious source of motivation and behavior no longer plays the primary role. This is not to suggest that conscious motivation and desire disappear. They do, however, seem to lose their overriding force. There is a sense of knowing what is real and centered. Life is perceived as more real than before and there is a new sense of appreciation of just being. 
The transformational process takes courage. As one is willing to change, as one is willing to let go, the process accelerates. People are able to accept change at different rates of speed and in different ways. People are able to trust, to let go, at different rates. The near-death experience needs to be integrated; listening to one's higher self is critical to maintaining peace and good health. If people are too preoccupied with struggling on a spiritual level, it holds them to a limited idea of who they are. It seems that the spirit can enter only when we are open to it, and the personality can trust and let go of fear.

Emotional love, as opposed to spiritual love, has to do with things like tenderness, sensuality, and sympathy. This type of love is generally connected with specific people, animals, and sometimes objects. NDErs talk about another kind of love, which I call spiritual love.

Perhaps it is because they have experienced the disconnection from the physical self; perhaps it is a reminder of the Light. People who have had NDEs frequently experience a quality of love that has less to do with reacting than with being. As Frank said, "Just be."

This quality of love within the individual opens up an understanding of the connectedness among living things on the planet. This awareness of the planetary connection brings about a new attitude, a loving and accepting attitude that offers a plan for hope, and can be seen as the only direction for survival in the evolution of mankind.

The sort of spiritual unfolding described above is fairly typical of the experiences of NDErs, as well as by those who have traveled similar roads through other doorways.

As I said above, the instruments used to score the NDErs show a limited ability to capture the meaning and the affect of the NDE. They do not tap the meaning-making that NDErs understand. Each person has a way of being here that allows him or her to learn what is necessary.

Thus the ability to learn, for NDErs, is more important than what the scores are.

\section{Implications for Future Studies}

The issue of the stage levels demonstrated by the near-death experiencers suggests a need for additional research in the field of developmental stage theory. We need to look at the various stages in a new way. Addressing the American Academy of Psychotherapists in October, 1987, Scott Peck announced that he is working with the Board of Examiners of the American Psychiatric Association to develop a spiri- 
tual history that will be incorporated into psychiatric interviews; it is hoped that instrument will produce additional or different data against which to assess the status of experiencers.

\section{Social Change}

As Teilhard de Chardin, Ring, and many others have been asking, can spiritual awakening precipitate the paradigm shift needed before social change can occur in this era?

The past thirty years have seen a remarkable increase in the number of hard scientists-Werner Heisenberg, Ilya Prigogine, David Bohm, and others-amenable to incorporating at least the concept of consciousness and spirituality into their thinking; in some cases, notably the younger physicists and biologists, there has been an acknowledgment of similarities between the principles of leading-edge science and spiritual traditions.

The participants in this study opened their hearts and lives without reservation in order to contribute to the new understandings reached in the area of NDEs and of God. Paul stated that he felt it a way to "experience the Radiance within," as a bridge to wholeness and enrichment for others, to respond to a world searching for a future without fear and for a shared understanding of love. Frank also said, "We need to believe it is possible to understand, and with this understanding we can then all lift from this level of fear and be ... one with God."

The two major impacts of the NDE for social change may be seen as follows:

1. A fundamental change in the perception of what death is. All experiencers share the view that death of the body is not death of the self.

2. The NDErs, as cells in an organism, can radiate a higher understanding to the entire society. If one person understands what these people understand, we are all able to do so. We need to learn to believe it is possible to understand what they know.

Maybe the higher meaning of the NDE is its contribution to the planetary paradigm shift to dissolve fear, to develop trust, to offer a plan for hope. The power of love may be what is necessary to save our future and promote universal harmony.

What conclusions can we draw from this research as far as the 
psychology of today is concerned? Frank's view - "All we need is love" -opens up the question. Why hasn't psychology put greater emphasis on love? Is it that psychology, as it has been practiced, has set forth separation instead of love? If so, why is this? Could it be that on a subtle level therapy is still hampered by fear? Is it fear of what could happen if we in loving confidence accept others as they are, instead of wanting to transform and control them into the models that we, from our theoretical standpoint, think are right?

We must make a commitment to love. For a person willing to help others, the commitment will involve much careful and active listening-a commitment to help another, to be whatever they need me to be, to do whatever needs to be done, and whatever will promote their growth, security, and well-being.

This may open a whole new way of helping each other. This may be the future of psychology, and the study of near-death experiences has been and is a vital contribution to this understanding. It is not just skills that cause the human heart to heal. It is the knowing from within, with certainty, that we can remember the order Frank remembers, to travel down the path of memory within the heart, our hearts lighted by love and hope, radiating outward and uniting with others in a spirit of joy and being. There is no bond like that of spiritual oneness. It is the real social solvent.

Intellect sets us apart from the things to be known, but love knows its object through fusion. Such knowledge is immediate and admits no doubt. It is the same as knowing ourselves, only more so. The knower and the known are one; unity and harmony are attained and expressed through love. The boundaries of the conscious self are melted and dissolved as love fills and flows through the human.

The near-death experience signifies the abolition of individuality, of definite separateness. It is a moment of heart seeking to transcend limitations of time, space, and personality, letting go and giving up the human ego, surrendering itself to the ultimate reality.

\section{References}

Atwater, P. M. H. (1988). Coming back to life. New York, NY: Dodd, Mead.

Blasi, A. (1976). Concept of development in personality theory. In J. Loevinger (Ed.), Ego development, pp. 29-53. San Francisco, CA: Jossey-Bass.

Conn, W. (1986). Christian conversion: $A$ developmental interpretation of autonomy and surrender. New York, NY: Paulist Press.

Ferguson, M. (1980). The Aquarian conspiracy. Los Angeles, CA: Tarcher. 
Flynn, C. (1986). After the beyond. Human transformation and the near-death experience. Englewood Cliffs, NJ: Prentice-Hall.

Fowler, J. (1981). Stages of faith: The psychology of human development and the quest for meaning. San Francisco, CA: Harper and Row.

Gilligan, C. (1982). In a different voice. Cambridge, MA: Harvard University Press.

Greyson, B., and Harris, B. (1987). Clinical approaches to the near-death experiencer. Journal of Near-Death Studies, 6, 41-52.

Kohlberg, L. (1981). Essays on moral development: Vol. I. Philosophy of moral development. New York, NY: Harper and Row.

Kohlberg, L. (1984). The measurement of moral judgment. New York, NY: Cambridge University Press.

Leonard, G. B. (1972). The transformation. Los Angeles, CA: Tarcher.

Loevinger, J. (1976). Ego development. San Francisco, CA: Jossey-Bass.

Moody, R. A., Jr. (1975). Life after life Covington, GA: Mockingbird Books.

Moody, R. A., Jr. (1977). Reflections on life after life. St. Simon's Island, GA: Mockingbird Books.

Naisbitt, J. (1982). Megatrends. New York, NY: Warner.

Parsons, T. (1951). The social system. Glencoe, IL: Free Press.

Ring, K. (1980). Life at death: $A$ scientific investigation of the near-death experience. New York, NY: Coward, McCann and Geoghegan.

Ring, K. (1984). Heading toward omega: In search of the meaning of the near-death experience. New York, NY: Morrow.

Sabom, M. B. (1982). Recollections of death: A medical investigation. New York, NY: Harper and Row.

Smith, H. (1976). Forgotten truth: The primordial tradition. New York, NY: Harper and Row.

Teilhard de Chardin, P. (1964). The future of man. New York, NY: Harper and Row. Toffler, A. (1970). Future shock. New York, NY: Random House.

Wilber, K. (1981). Up from Eden. Boulder, CO: Shambhala. 